\title{
HIV-1 Envelope Glycoprotein 120 Increases Intercellular Adhesion Molecule-1 Expression by Human Endothelial Cells
}

\author{
Zeguang Ren, Qizhi Yao, and Changyi Chen \\ Departments of Surgery (ZR, CC) and Microbiology and Immunology (QY), Emory University School of Medicine, \\ Atlanta, and Department of Surgery (CC), Atlanta Veterans Affairs Medical Center, Decatur, Georgia
}

\begin{abstract}
SUMMARY: Human immunodeficiency virus type 1 (HIV-1) infection is often associated with central nervous system damage and vascular complications. However, the mechanisms of this association are largely unknown. We examined the effect of HIV-1 envelope glycoprotein 120 (gp120) on cell adhesion molecule expression by endothelial cells. We found, for the first time, that both soluble and membrane-bound gp120 could significantly increase the expression of human endothelial intercellular adhesion molecule-1 (ICAM-1) at both mRNA and protein levels, but not vascular cell adhesion molecule-1 and E-selectin. The specificity of gp120-mediated response was demonstrated by blocking experiments using a specific monoclonal antibody against gp120, which successfully abolished the gp120-mediated increase of ICAM-1 expression. Furthermore, there was a significant increase of human monocytic cell line THP-1 adherence onto the gp120-treated endothelial monolayers. This increased cell adhesion was effectively blocked by either anti-gp120 or anti-ICAM antibodies. These findings suggest that HIV-1 gp120-mediated endothelial ICAM-1 expression could be one of the important mechanisms of HIV-1 pathogenesis. (Lab Invest 2002, 82:245-255).
\end{abstract}

$B$ oth human immunodeficiency virus (HIV)-positive and acquired immune deficiency syndrome (AIDS) patients often have significantly increased levels of circulating cell adhesion molecules, such as intercellular adhesion molecule-1 (ICAM-1) and vascular adhesion molecule-1 (VCAM-1) (Greenwood et al, 1998; Seigneur et al, 1997). Serum ICAM-1 levels correlate well with AIDS progression in HIV type 1 (HIV-1)-infected patients (Galea et al, 1997). Endothelial cells and leukocytes from these patients exhibit a significant increase of such adhesion molecules (Pillet et al, 1999; Zietz et al, 1996). HIV-1 particles also incorporate many cell adhesion molecules (Guo and Hildreth, 1995). HIV-associated ICAM-1 is biologically active and can enhance virus infectivity (Fortin et al, 1997) and virus-induced syncytium formation (Gruber et al, 1991). ICAM-1-bearing viruses are less susceptible to neutralization by anti-envelope glycoprotein 120 (gp120) monoclonal antibodies than the same virus produced in cells expressing no ICAM-1 (Sawyer et al, 1994). HIV-1 replication in monocytes/macrophages is significantly enhanced by interaction with endothelial cells through cell adhesion molecules (Gilles et al, 1995). In addition, alterations in expression of cell adhesion molecules by leukocytes and

\section{Received July 6, 2001}

This work was supported by grants HL61943, HL65916, and HL60135 (CC) from the National Institutes of Health.

Address reprint requests to: Dr. Changyi (Johnny) Chen, Department of Surgery, Emory University School of Medicine, 1639 Pierce Drive, Surgical Research, 5105 Woodruff Memorial Building, Atlanta, Georgia 30322. E-mail:jchen03@emory.edu endothelial cells can increase leukocyte migration into the tissues, which may result in certain organ damage. Indeed, HIV-1-infected leukocytes can transmigrate into the central nervous system and cause encephalopathy (Nottet, 1999). Endothelial cell dysfunction and leukocyte infiltration may also be attributable to the increased frequency of vascular complications such as atherosclerosis in HIV-1-infected patients (Constans et al, 1995; Tabib et al, 2000).

Several factors may contribute to the increased levels of cell adhesion molecules in HIV-1 infection. Elevated levels of proinflammatory cytokines such as TNF- $\alpha$ and IL- $1 \beta$ have been detected in serum of AIDS patients and in macrophages isolated from HIV-1infected individuals (Butl et al, 1993; Lahdevirta et al, 1988). Clearly, these cytokines are able to induce expression of endothelial adhesion molecules. HIV-1infected monocytes/macrophages are able to induce the expression of E-selectin and VCAM-1 on brain microvascular endothelial cells (Lahdevirta et al, 1988). Furthermore, HIV-1 appears to be permissive for infection of brain endothelium (Moses et al 1993) and microvascular endothelium from liver sinusoids (Cenacchi et al, 1992), kidney glomerulus (Green et al, 1992), and adipose tissue (Steffan et al, 1992). Thus, direct HIV-1 infection might also activate these endothelial cells. On the other hand, HIV-1 viral proteins such as Tat and envelope glycoproteins may be involved in endothelial cell activation. Treatment of human umbilical vein endothelial cells (HUVECs) or human microvascular endothelial cells with Tat induces the cell surface expression of ICAM-1, VCAM-1, and E-selectin (Dhawan et al, 1997; Mrowiec 
et al, 1997). Circulating HIV-1 gp120 is found in HIV-1-infected individuals and it could be derived from shedding during viral turnover (Oh et al, 1992). HIV-1 gp120 is able to up-regulate ICAM-1 expression in glial cells through the activation of protein kinase $C$ and tyrosine kinase (Shrikant et al, 1996). Peripheral blood mononuclear cell (PBMC) cultures exposed to gp120 have a dose-dependent increase of ICAM-1 expression (Capobianci, 1996). HIV-1 gp41 could also enhance ICAM-1 expression on $\mathrm{H} 9$ monocytoid cell line (Chen et al, 1994). In addition, gp120 could enhance monocyte adhesion to the exposed endothelial cells of both human saphenous vein and internal thoracic arteries in vitro (Stefano et al, 1998). However, little is known about the direct effect of gp120 on cell adhesion molecule expression by endothelial cells. It is believed that HIV-1-mediated endothelial dysfunction, including alteration of cell adhesion molecule expression, could have significant clinical consequences on HIV-1 infection, and it could affect virus infectivity, disease progression, neuropathogenesis, and atherosclerosis in the patients. In this study, we have investigated whether HIV-1 gp120, both in soluble and membrane-bound forms, could induce cell adhesion molecule expression by several types of endothelial cells. The observations made in this study suggest that HIV-1 gp120 increases ICAM-1 expression, but not VCAM-1 and E-selectin, by endothelial cells as well as enhances monocyte cell adhesion to the gp120-treated endothelial cells.

\section{Results}

\section{HIV-1 gp120 Increases ICAM-1 mRNA Expression by Several Types of Endothelial Cells}

To test whether recombinant HIV-1 gp120 could induce cell adhesion molecule expression by endothelial cells, we initially used immortalized human dermal microvascular endothelial cells (HMECs) (Ades et al, 1992) with treatment of soluble gp120, and analyzed ICAM-1, VCAM-1, and E-selectin expression using RT-PCR. Incubation of HMECs with gp120 (5 $\mu \mathrm{g} / \mathrm{ml})$ enhanced ICAM-1 mRNA expression in a timedependent manner (Fig. 1A). HMECs constitutively expressed low levels of ICAM-1 mRNA, which was maximally enhanced up to $140 \pm 10 \%$ by 8 - and 16-hour treatments with gp120 ( $p<0.05 ; n=4)$. Having established the optimal kinetics of expression, we performed dose-response experiments to determine the concentrations of HIV-1 gp120 that effectively enhanced ICAM-1 mRNA expression. We cultured HMECs with treatment of different doses of gp120 for 16 hours, and showed that ICAM- $1 / \beta$-actin density increased significantly by $65 \%, 89 \%$, and $111 \%$, corresponding to $0.5-, 5-$, and $10-\mu \mathrm{g} / \mathrm{ml} \mathrm{gp} 120$ treatments, respectively, compared with controls without gp120 treatment (Fig. 1B; $p<0.05 ; n=4$ ).

To further confirm the effect of HIV-1 gp120 on ICAM-1 expression, we used four types of human primary endothelial cells, including dermal microvascular endothelial cells (MECs), HUVECs, lung micro-
$\mathbf{A}$
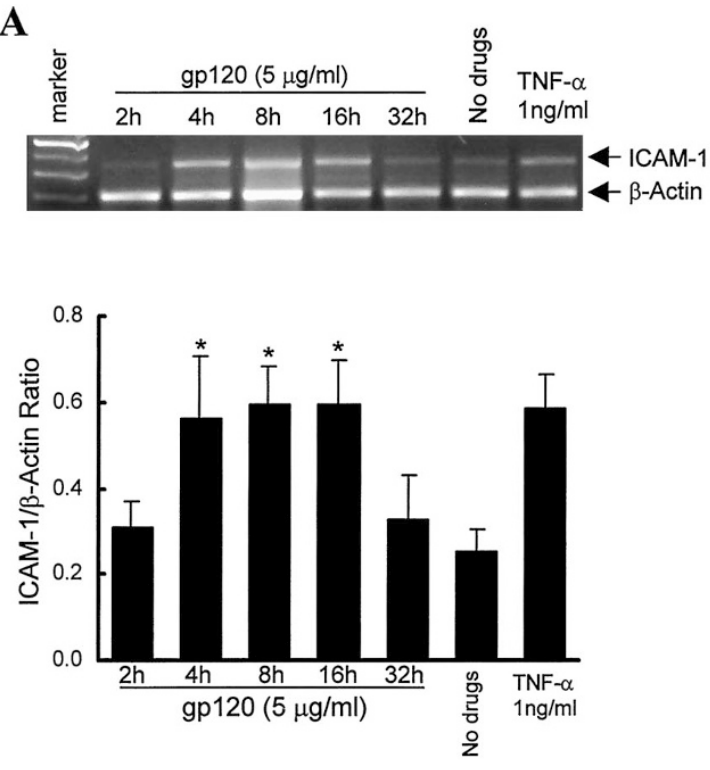

B
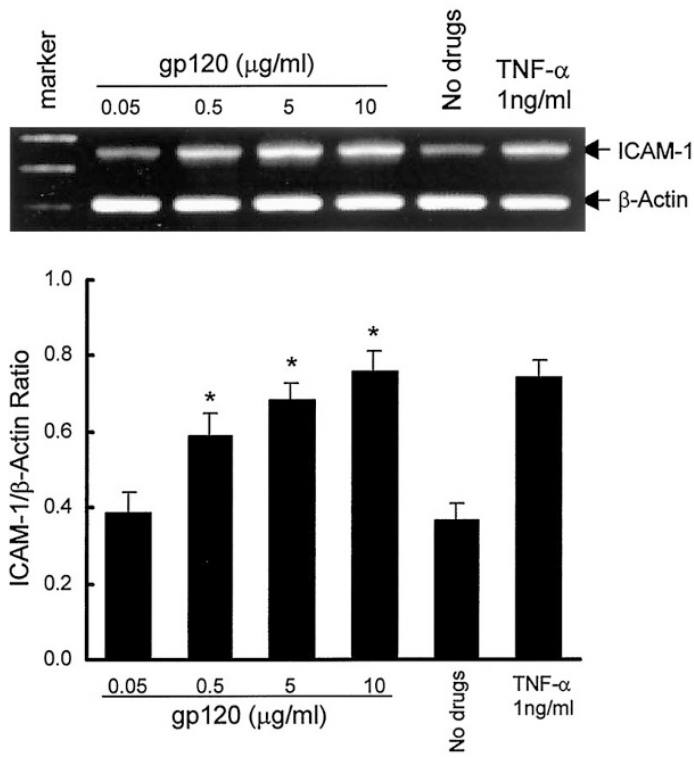

Figure 1.

Soluble Human immunodeficiency virus-1 (HIV-1) envelope glycoprotein 120 (gp120) increases intercellular adhesion molecule-1 (ICAM-1) mRNA expression by human dermal microvascular endothelial cells (HMECs). A, Timecourse study showing that, by semiquantitative RT-PCR analysis, the treatment of gp120 $(5 \mu \mathrm{g} / \mathrm{ml})$ significantly enhanced endothelial ICAM-1 mRNA expression. The maximal ICAM-1 expression is at 8 and 16 hours after treatment. B, Dose-dependent study showing that the treatment with gp120 for 16 hours stimulates endothelial ICAM-1 expression in the dose ranging from 0.05 to 10 $\mu \mathrm{g} / \mathrm{ml}$. The gp120 treatment at $0.5,5$, and $10 \mu \mathrm{g} / \mathrm{ml}$ shows a significant stimulating effect. * $p<0.05$ compared with the no-drug-treated group ( $n=$ 4). The no-drug treatment group acted as a negative control. TNF- $\alpha$ treatment group acted as a positive control.

vascular endothelial cells (HMVECs-L), and coronary artery endothelial cells (HCAECs) and analyzed ICAM-1 expression after treatment of gp120 (5 $\mu \mathrm{g} / \mathrm{ml})$ for 16 hours. Like HMECs, all primary cell types showed a significant increase of ICAM-1 expression, except for HUVECs, which had a limited increase (Fig. 2). In addition, to test whether membrane-associated gp120 could induce cell adhesion molecular expres- 


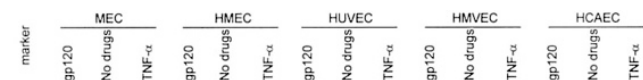
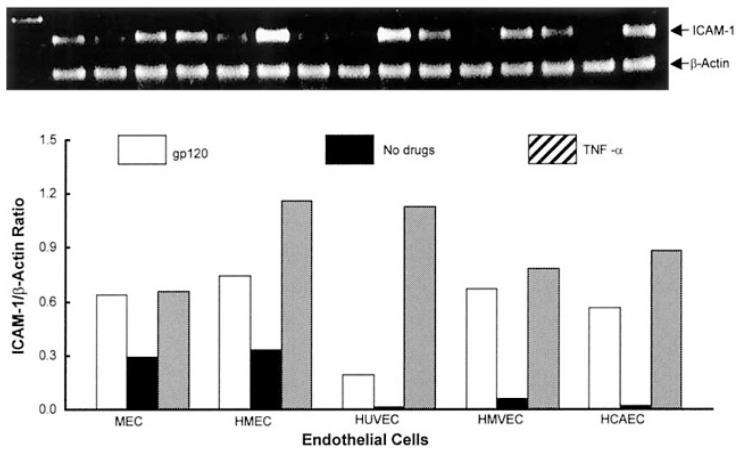

Figure 2.

Soluble HIV-1 gp120 increases ICAM-1 mRNA expression by several types of endothelial cells. RT-PCR analysis demonstrating that HMECs, microvascular endothelial cells (MECs), human lung microvascular endothelial cells (HMVECs-L), and human coronary artery endothelial cells (HCAECs) show a significant ICAM-1 expression on the stimulation of gp120 $(5 \mu \mathrm{g} / \mathrm{ml})$ for 16 hours, but human umbilical vein endothelial cells (HUVECs) exhibit only a limited increase of ICAM-1 expression. Duplicate experiments were performed.

sion by endothelial cells, we used HIV-1 virus-like particles (VLPs) (Yao et al, 2000) to treat HMEC cultures. RT-PCR results showed that HIV-1 VLPs also induced ICAM-1 expression (Fig. 3A), but not VCAM-1 (Fig. 3B) and E-selectin (data not shown). These data were confirmed by duplicated experiments.

\section{HIV-1 gp120 Enhances ICAM-1 Protein Expression by HMECs}

ICAM-1 expression can be modulated at the transcriptional, post-transcriptional, and/or translational level depending on the nature of the stimulus (Shrikant et al, 1994). We thus examined whether the increase in ICAM-1 steady state mRNA levels corresponded with an increase in ICAM-1 protein expression. We assessed ICAM-1 cellular protein expression using immunofluorescence staining. HIV-1 gp120 treatment
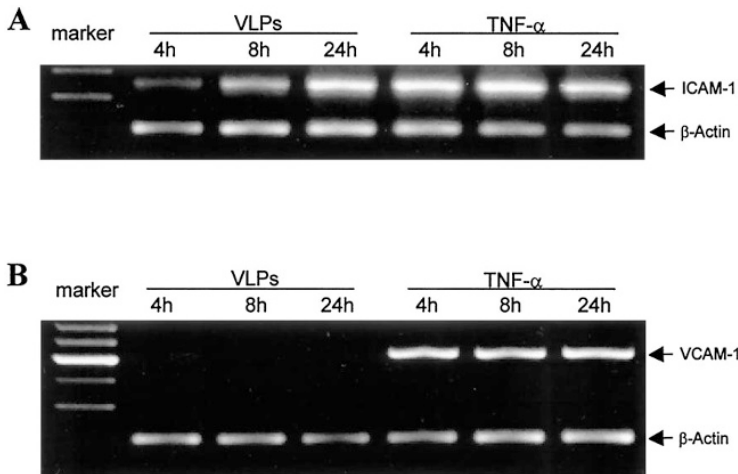

\section{Figure 3.}

HIV-1 virus-like particles (VLP) enhance the mRNA expression of ICAM-1, but not of vascular adhesion molecule-1 (VCAM-1), by HMECs. A, Time course study indicating that ICAM-1 mRNA is significantly expressed at 8 and 24 hours after the treatment of HIV-1 VLPS $(50 \mu \mathrm{g} / \mathrm{ml})$. B, Time course study showing no VCAM-1 expression after the same treatment of HIV-1 VLPs. Duplicate experiments were performed. increased ICAM-1 protein expression in HMECs as compared with the untreated cells (Fig. 4A). We also collected supernatants of cell cultures and determined soluble ICAM-1 levels using ELISA analysis. Consistent with ICAM-1 mRNA and cellular protein expression data, HIV-1 gp120 significantly increased soluble ICAM-1 production by $92 \%$ as compared with untreated controls (Fig. 4B; $p<0.01 ; n=3$ ).

\section{Anti-gp120 Antibody Blocks HIV-1 gp120-Induced ICAM-1 Expression by HMECs}

To test whether a neutralizing monoclonal antibody against HIV-1 gp120 could block gp120-induced ICAM-1 expression, we treated HMECs with a mixture of the antibody and soluble gp120, and analyzed ICAM-1 mRNA, cellular protein expression, and secreted ICAM-1 levels. HIV-1 gp120 (5 $\mu \mathrm{g} / \mathrm{ml})$ combined with different doses of the antibody $(0.1,1,10$, $20 \mu \mathrm{g} / \mathrm{ml}$ ) significantly attenuated the effect of gp120induced ICAM-1 mRNA expression in a dosedependent manner (Fig. $5 ; p<0.05 ; n=3$ ). Antigp120 antibody treatment also reduced gp120enhanced cellular ICAM-1 protein expression as demonstrated by less immunofluorescence staining intensity (Fig. 4A). Furthermore, the anti-gp120 antibody significantly decreased gp120-induced ICAM-1 protein secretion by $54 \%$ as compared with gp120 treatment alone (Fig. 4B; $p<0.05 ; n=3$ ). Thus, these data demonstrate the specificity of gp120-mediated ICAM-1 expression by human endothelial cells.

\section{HIV-1 gp120 Treatment Increases Monocyte Adhesion onto the HMEC Monolayer}

To test the effect of HIV-1 gp120 on monocyte adherence, we analyzed the ability of THP-1 cells (monocytic cell line) to adhere to unstimulated or gp120stimulated HMECs. We labeled THP-1 cells with a fluorescent compound (BCECF-AM) then allowed them to adhere to a monolayer of HMECs that had been previously exposed to medium or gp120 for 16 hours. After a proper wash procedure, we examined adherent THP-1 cells on the HMEC monolayer using a computer-assisted fluorescence microscope and image analysis system. There was a minimal adherence of THP-1 cells to untreated HMECs, whereas in cultures containing gp120-activated HMECs, adherence of THP-1 cells was significantly enhanced over that in control cultures by 3.26-fold (Fig. 6 ; $p<0.01$; $n=6$ ). This enhanced binding was inhibited approximately $64 \%$ on the inclusion of anti-gp120 antibody $(p<$ $0.01 ; n=6)$. Furthermore, the antibody against ICAM-1 also significantly reduced THP-1 adhesion onto gp120-treated HMECs by $53 \%$ as compared with those without anti-ICAM-1 antibody treatment (Fig. 6; $p<0.01 ; n=6$ ). These results indicate that monocytic cell line THP-1 adheres to gp120stimulated HMECs via interactions involving endothelial ICAM-1 molecules. 

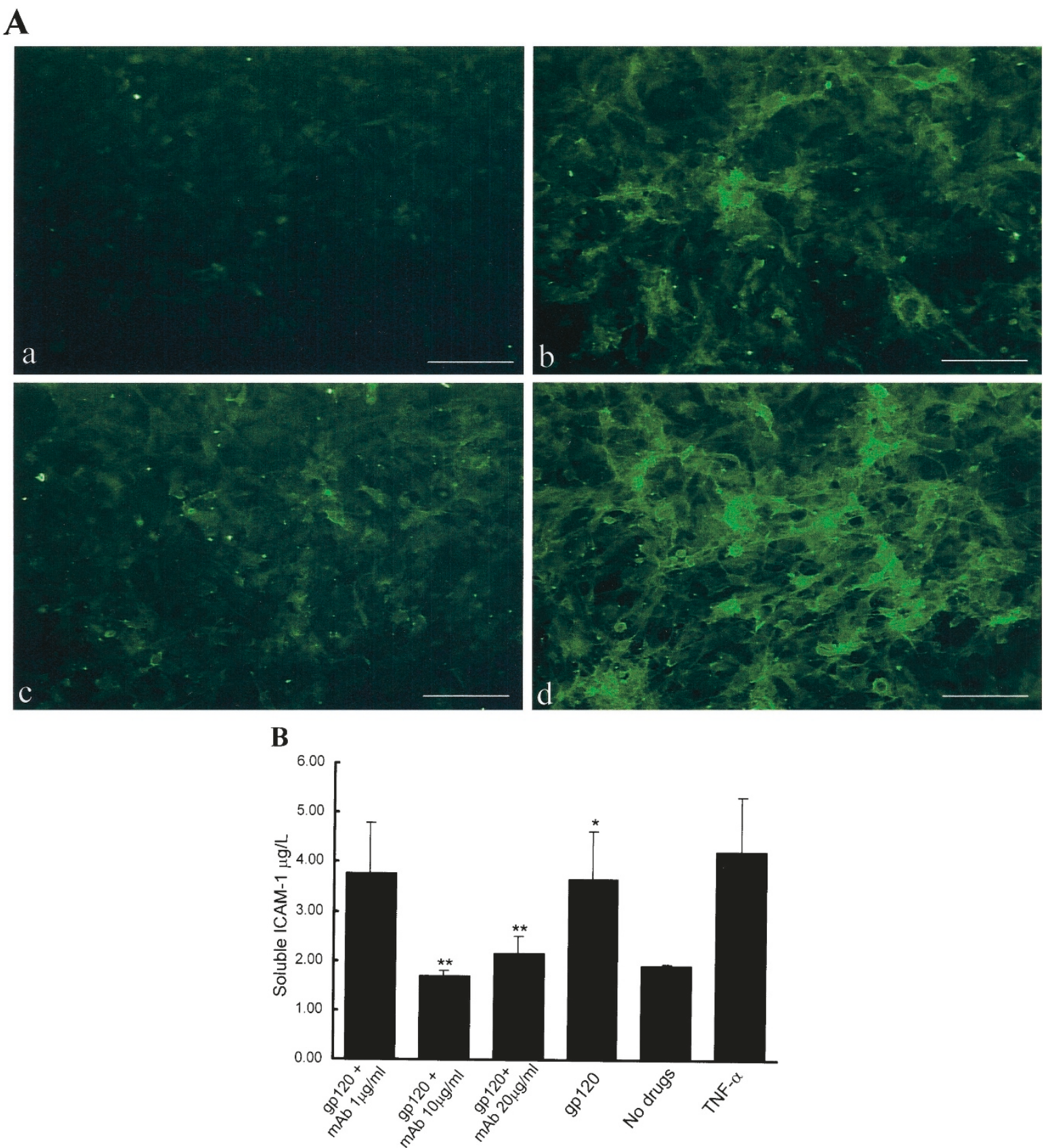

Figure 4.

Soluble HIV-1 gp120 increases ICAM-1 protein levels in both cellular expression and secreted form in HMECs. A, Immunofluorescence microscopy (original magnification, $\times 200$ ) showing that gp120 treatment $(5 \mu \mathrm{g} / \mathrm{ml})$ for 16 hours enhances ICAM-1 cellular expression in HMECs (b) as compared with untreated cells (a). This effect of gp120 is blocked by anti-gp120 antibody (c). TNF- $\alpha$-treated group acted as positive control (d). Scale bar, $100 \mu \mathrm{m}$. B, ELISA analysis demonstrating that gp120 treatment $(5 \mu \mathrm{g} / \mathrm{ml})$ for 16 hours significantly increases the levels of secreted ICAM-1 protein from HMECs. This effect is also inhibited by the anti-gp120 antibody in a dose-dependent manner. ${ }^{*} p<0.01$ compared with the no-drug treatment group $(n=3) .{ }^{* *} p<0.05$ compared with the gp120 treatment group without antibody $(n=3)$.

\section{Discussion}

In this study, we examined the effect of HIV-1 gp120 on cell adhesion molecule expression by endothelial cells. We found, for the first time, that soluble HIV-1 gp120 significantly increased the expression of endothelial ICAM-1, but not VACM-1 and E-selectin, in a time- and dose-dependent manner. This effect was reflected by an enhancement of both ICAM-1 mRNA and protein levels, including cellular expression and secreted form. The specificity of gp120-mediated response was demonstrated by blocking experiments using a specific monoclonal antibody against gp120, which successfully abolished a gp120-mediated increase of ICAM-1 expression in several types of endothelial cells. In addition, membrane-bound gp120 of HIV-1 VLPs was also able to increase ICAM-1 expression of human endothelial cells. These obser- 

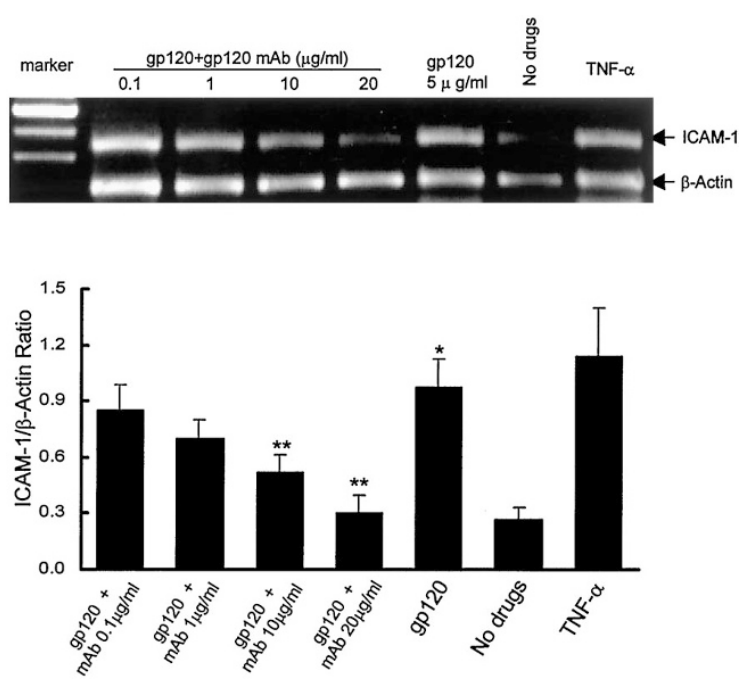

Figure 5.

Monoclonal antibody against HIV-1 gp120 effectively inhibits gp120stimulated ICAM-1 mRNA expression by HMECs. RT-PCR analysis demonstrating that gp120 treatment $(5 \mu \mathrm{g} / \mathrm{ml})$ for 16 hours significantly increases the ICAM-1 mRNA expression by HMECs. This effect is significantly inhibited by the anti-gp120 antibody in a dose-dependent manner. ${ }^{*} p<0.05$ compared with the no-drug treatment group $(n=3) .{ }^{* *} p<0.05$ compared with the gp120 treatment group without antibody $(n=3)$.

vations demonstrate that HIV-1 gp120 alone can activate human vascular endothelium, indicating that this increased ICAM-1 may facilitate leukocyte adhesion onto the endothelium. Indeed, we found there was a significant increase of human monocytic cell line THP-1 adherence onto the gp120-treated endothelial monolayers as compared with the untreated endothelial monolayers. This increased cell adhesion was effectively blocked by either anti-gp120 or antiICAM-1 antibodies.

Although the direct effect of HIV-1 envelope proteins on endothelial ICAM-1 expression has not been reported previously, HIV-1 gp120 or gp41 is capable of inducing ICAM-1 expression in other cell types, such as glial cells and leukocytes (Capobianci 1996; Chen et al, 1994; Shrikant et al, 1996). Shrikant et al (1996) reported that treatment of primary rat astrocytes and microglia with recombinant HIV-1 gp120 significantly enhanced ICAM-1 mRNA expression and cellular ICAM-1 protein levels. The optimal enhancement was at 2 hours after exposure of gp120. However, it is not clear whether gp120 affects the expression of other cell adhesion molecules such as VCAM-1 and E-selectin in these glial cells. In our study, several types of human endothelial cells were used, and they were derived from different sources, including human skin, lung, coronary, and umbilical cords. All cell types except for HUVECs strongly expressed ICAM-1 in response to the HIV-1 gp120. ICAM-1 expression reached maximal response after 8 hours of gp120 treatment. As well as ICAM-1 expression, we also demonstrated that soluble HIV-1 gp120 did not affect VCAM-1 and E-selectin expression in endothelial cells. In addition, membrane-bound gp120 of HIV-1 VLPs also showed a significant enhancement of ICAM-1 expression, but not VCAM-1 and E-selectin, in human endothelial cells. Capobianchi (1996) observed a dose-dependent increase of the expression of ICAM-1 in PBMC cultures exposed to recombinant HIV-1 gp120. Interestingly, Chen et al (1994) reported that soluble HIV-1 gp41 enhanced ICAM-1 expression by $70 \%$ on monocytic cell line $\mathrm{H} 9$, but did not affect U937 cells, suggesting a selective biologic function of gp41 that is involved in the regulation of ICAM-1 expression. Moreover, a transgenic mouse model for HIV-1 gp120 has been established with secreted circulating levels of gp120 similar to those detected in AIDS patients (Finco et al, 1997), and significant up-regulation of ICAM-1 on brain endothelial cells has been found in this animal model (Toneatto et al, 1999). Thus, HIV-1 gp120 can directly increase ICAM-1 expression in several cell types, including endothelial cells, glial cells, and leukocytes.

Our results demonstrate a functional correlate for gp120-mediated ICAM-1 expression by endothelial cells, and increased adhesion of the monocytic cell line THP-1 to gp120-stimulated endothelial cells. This interaction was effectively blocked by $53 \%$ when endothelial cells were incubated with a monoclonal antibody to ICAM-1, indicating a specific interaction between monocytes and endothelial cells via ICAM-1. However, the complete inhibition of THP-1 cell adhesion by anti-ICAM-1 antibody was not achieved, suggesting other molecules, such as ICAM-2 and ICAM-3, may be involved in this adhesion event induced by gp120. There is evidence that ICAM-2 and ICAM-3, in addition to ICAM-1, can function as ligands in HIVmediated syncytia formation (Butini et al, 1994). Thus, it will be important to determine whether gp120 affects the expression of ICAM-2 and/or ICAM-3 in endothelial cells. Stefano et al (1998) showed a direct effect of HIV-1 gp120 on enhancement of human monocyte adherence to the endothelial surface of human saphenous vein and internal thoracic artery segments in vitro. Although the expression of cell adhesion molecules was not studied, this enhanced monocyte adhesion appeared to result from endothelial nitric oxide synthase (eNOS) inhibition and decreased NO production by gp120-treated endothelial cells, because NO is an inhibitor of monocyte-endothelium adhesion (Adams et al, 1997). Another study demonstrated that treatment of CD4+ T cells with gp120 significantly altered their interaction with endothelium (Bragardo et al, 1997). HIV-1 gp120 treatment increased dynamic binding of lymphocytes to HUVECs in a dosedependent manner in vitro as well as increased the early homing of lymphocytes into the spleen and the late homing into peripheral lymph nodes in a mouse model (Bragardo et al, 1997). Cocapping analysis indicated that the intermolecular aggregations induced by gp120 might alter lymphocyte adhesion to endothelium by inducing the formation of multimolecular adhesive patches (Bragardo et al, 1997). Therefore, HIV-1 gp120 can directly enhance adhesion between leukocytes and endothelial cells by an increase of cell adhesion molecule expression or by other mechanisms, such as eNOS activity and aggregations of cell surface molecules. 
A
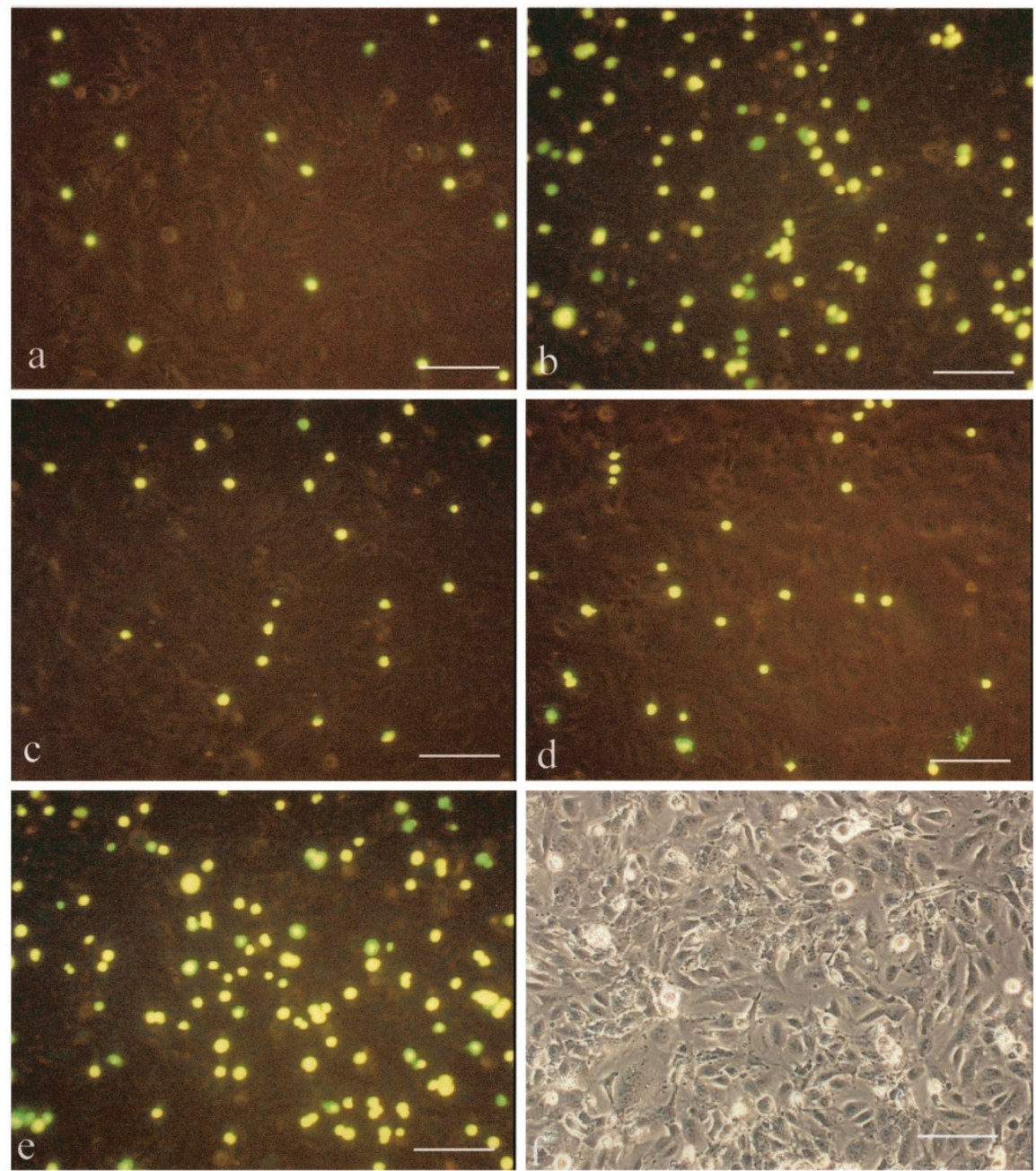

B

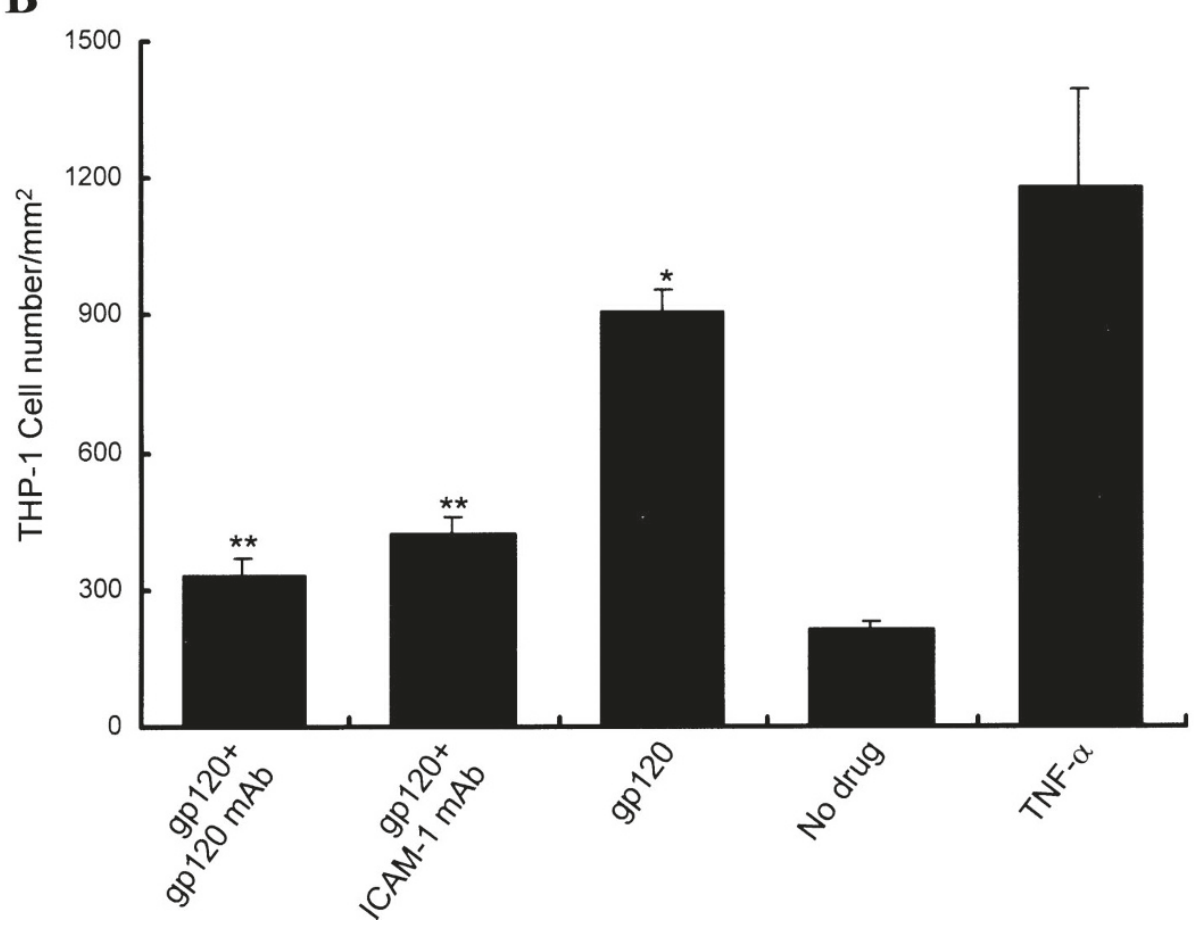


How HIV-1 gp120 induces the ICAM-1 expression by endothelial cells is not clear. It has been shown that the promoter for several adhesion molecules, including ICAM-1, contains a nuclear factor $-\kappa \mathrm{B}(\mathrm{NF}-\kappa \mathrm{B})$ element that is essential for transcription. TNF- $\alpha$ induces ICAM-1, VCAM-1, and E-selectin via activation of NF- $\kappa \mathrm{B}$ (Collins et al, 1995). Unlike TNF- $\alpha, \mathrm{HIV}-1$ gp120 only selectively increased ICAM-1 expression by endothelial cells in this study. Thus, we speculate that HIV-1 gp120 may have a different mechanism for the induction of ICAM-1 expression than TNF- $\alpha$. Such differences have not been studied in endothelial cells. However, they have been observed in HIV-1 Tatmediated expression of cell adhesion molecules. It has been reported that HIV-1 Tat by itself does not activate $\mathrm{NF}-\kappa \mathrm{B}$, but rather potentiates the TNF- $\alpha-$ mediated activation of NF- $\kappa \mathrm{B}$ (Westendorp et al, 1995). This potentiation was due to a change in the redox state of the cells caused by down-regulation of magnesium superoxide dismutase (Mn-SOD) expression (Flores et al, 1993; Westendorp et al, 1995). In contrast to Tat, gp120 is unable to inhibit activity and expression of Mn-SOD, but it can amplify TNF- $\alpha-$ induced NF- $\kappa$ B-binding activity in CD4-positive Jurkat T cells (Shatrov et al, 1996). Although the direct effect of gp120 on TNF- $\alpha$ expression in endothelial cells has not been determined, our data imply that TNF- $\alpha$ may not be involved in gp120-mediated endothelial ICAM-1 expression because the expression of VCAM-1 and E-selectin are not affected by gp120 treatment. Unlike HIV-1 gp120, TNF- $\alpha$ is a potent inducer for expression of all ICAM-1, VCAM-1, and E-selectin in endothelial cells (Cominacini et al, 1999; Kalogeris et al, 1999). In glial cells, inclusion of a neutralizing antibody against TNF- $\alpha$ does not block gp120-induced ICAM-1 expression, suggesting a direct effect of gp120 on ICAM-1 gene expression (Shrikant et al, 1996). HIV-1 gp120 induces tyrosine phosphorylation of signal transducer and activator of transcription (STAT-1 $\alpha$ ) as well as the Janus kinase (JAK2) in glial cells (Shrikant et al, 1996). Conversely, other studies suggest that the up-modulation of ICAM-1 in PBMC is not directly induced by HIV-1 gp120, but it may be mediated by the action of gp120-induced cytokines, such as TNF- $\alpha$, IL-10, and interferon (Capobianci, 1996). Thus, HIV-1 gp120 seems to exhibit different mechanisms for modulation of ICAM-1 expression in different cell types.

HIV-1 gp120-mediated up-regulation of endothelial ICAM-1 may have clinical significance in HIV-1 pathogenesis. It could influence the intercellular communication events involved in immune cross-talking and in the leukocyte-endothelium multistep interactions
(Springer, 1994), and it could be involved in the cell-mediated transmission of HIV-1 infection (Scheglovitova et al, 1995). Increased ICAM-1 expression determines a stimulation of the transmission of HIV-1 from abortively infected endothelial cells to permissive CD4 lymphocytes (Scheglovitova et al, 1995). Furthermore, increased leukocyte-endothelium interaction enhances HIV-1 replication in in vitro infected macrophages and chronically infected monocytic cell lines (Borghi et al, 2000; Gilles et al, 1995). Anti-ICAM-1 antibody strongly inhibits adherence of monocytes to endothelial monolayers, and such treatments also result in the reduction of HIV-1 particle formation (Scheglovitova et al, 1995). Because endothelial cells lining blood vessels are important components of the blood-tissue barriers, it is possible that increased endothelial ICAM-1 expression could enable HIV-1 to cross anatomical barriers and to invade otherwise inaccessible body districts, such as the central nervous system (Scheglovitova et al, 1995). Evidence indicates that ICAM-1 is the predominant endothelial molecule governing lymphocyte or monocyte adhesion to and migration through central nervous system endothelium (Scheglovitova et al, 1995). Indeed, a large number of lymphocytes and monocytes are seen in the brain tissues of HIV-1-infected patients who suffer from AIDS dementia complex (Nottet, 1999; Nottet et al, 1996). HIV-1 infection is also associated with an increased frequency of vascular complications such as atherosclerosis (Constans et al, 1995; Tabib et al, 2000). Up-regulation of endothelial ICAM-1 could promote monocyte infiltration into the vascular wall, contributing to vascular lesion formation. Tabib et al (2000) examined coronary lesions in corpses of patients infected with HIV-1 who had died young. The lesions were constituted by hyperplastic endothelial cells lining a thickening of intima, which was composed of the proliferation of smooth muscle cells and monocytic macrophages. It is interesting to note that the vascular lesions associated with simian immunodeficiency virus in monkeys and with HIV-1 infection in children are morphologically identical (Chalifoux et al, 1992). By immunohistochemical examination, increased ICAM-1 expression is correlated with monocyte infiltration in the vascular wall of the HIV-infected patients (Pillet et al, 1999; Tabib et al, 2000; Zietz et al, 1996;). In addition to HIV-1, ICAM-1 could also be subverted by viruses as receptors for cell infectivity, including rhinoviruses, Coxsackie viruses, and poliovirus (White and Littman, 1998). Additionally, ICAM-1 is one of two receptors characterized for Plasmodium falciparum-infected erythrocytes (Berendt et al, 1989). A key event in malaria is the sequestration of infected

\footnotetext{
Figure 6.

Monocytic cell line THP-1 increases its adhesion to the gp120-treated HMEC monolayer. THP-1 cells were labeled with a fluorescence dye. HMEC monolayers were treated with gp120 (5 $\mathrm{g} / \mathrm{ml})$ for 16 hours. A, Fluorescence microscopy (original magnification, $\times 200)$ showing that there is a significant increase of THP-1 cell adhesion to the gp120-treated HMEC monolayer (b) as compared with the untreated monolayer (a). This enhancement of THP-1 cell adhesion is significantly inhibited by both anti-gp120 antibody (10 $\mu \mathrm{g} / \mathrm{ml})$ (c) and anti-ICAM-1 antibody $(10 \mu \mathrm{g} / \mathrm{ml})(\mathrm{d})$. TNF- $\alpha(1 \mathrm{ng} / \mathrm{ml})$ treatment acted as a positive control (e). Phase contract microscopy showing similar HMEC cell density for all adhesion experiments (f). Scale bar, $100 \mu \mathrm{m}$. B, Quantitation of THP-1 cell adhesion by image analysis showing the corresponding results to Panel A. * $p<0.01$ compared with the no-drug treatment group $(n=6) .{ }^{* *} p<0.01$ compared with the gp120 treatment group without antibody $(n=6)$.
} 
erythrocytes in the cerebral microvasculature, and ICAM-1 may play a role in this process. Therefore, HIV-1 gp120-induced endothelial ICAM-1 expression could contribute to organ damage and AIDS progression in HIV-1-infected patients.

Recent investigations have revealed several other effects of HIV-1 gp120 on endothelial functions in addition to its induction of endothelial ICAM-1 in this study. Annunziata et al (1998) has demonstrated that recombinant HIV-1 gp120 increases the permeability of rat brain endothelial cell cultures. This effect has also been confirmed by a model of transgenic mice for gp120 (Toneatto et al, 1999). Two recent studies have shown that HUVECs undergo apoptosis after their treatment with gp120 (Huang et al 1999; Ullrich et al, 2000). Chemokine receptors appear to mediate this process. The gp120 protein used in our experiments is derived from the HIV-1-IIIB isolate, which has been previously described as the prototype T-cell tropic isolate (Bazan et al, 1998). Differential patterns of chemokine receptor usage have been shown in studies, suggesting that the IIIB-derived clone HXB2 binds the CXCR4 receptor in preference to the CCR5 receptor (Bazan et al, 1998). In our study, we have also demonstrated that all types of endothelial cells used in the experiments are expressing CCR 5 and CXCR4 by both flow cytometry analysis and immunofluorescence staining (data not shown), but it is not clear whether these chemokine receptors mediate the effects of gp120 on endothelial ICAM-1 expression. This issue is currently under active investigation in our laboratory. Furthermore, gp120 could bind to brain endothelial cells by a mechanism resembling adsorptive endocytosis (Banks et al, 1997). This vesicularbased internalization is stimulated by the plant lectin wheatgerm agglutinin and cytokines, and provides a pathway by which free viruses and infected immune cells could cross the blood-brain barrier (Banks et al, 1999). More evidence suggests that gp120 initially binds to $\mathrm{N}$-acetylglucosamine on the brain endothelial cell surface with postinternalization membrane fusion involving a chemokine receptor (Banks et al, 1998). Thus, HIV-1 gp120 could exhibit several different mechanisms to interact with endothelial cells resulting in endothelial dysfunction.

\section{Materials and Methods}

\section{Cells}

The immortalized HMECs (Ades et al 1992) and primary culture of human dermal MECs were obtained from Dr. Wright S. Caughman, Department of Dermatology, Emory University (Atlanta, Georgia). HMVECs-L, HCAECs, and HUAECs were purchased from Clonetics Corporation (Walkersville, Maryland). HMECs and MECs were cultured as previously described (Ades et al, 1992). HUVECs, HMVECs-L, and HCAECs were cultured according to the instruction provided with the cells. When the cells grew to $80 \%$ to $90 \%$ confluence, the different drugs were added to the medium. At a proper time point, the medium and cells were collected for analysis of
ICAM-1 expression. THP-1, one leukemia monocytic cell line, was obtained from American Type Culture Collection (ATCC; Manassas, Virginia). THP-1 cells were cultured as instructed by ATCC.

\section{Proteins and Antibodies}

HIV-1 gp120 and anti-gp120 monoclonal antibody (mAb) were obtained from the National Institutes of Health AIDS Research and Reference Reagent Program (Rockville, Maryland). HIV VLPs were produced in a baculovirus expression system, as described previously (Yao et al, 2000). The sources of other antibodies used for the experiments were as follows: anti-Von Willebrand factor antibody (polyclonal) and anti-ICAM-1 mAb (DAKO, Carpinteria, California), and fluorescein-conjugated goat anti-mouse antibody and rhodamine-conjugated goat anti-rabbit antibody (ICN/Cappel, Aurora, Ohio). Serial concentrations of anti-gp120 and anti-ICAM-1 antibodies were used for blocking experiments. Recombinant human TNF- $\alpha$ (GIBCO BRL, Gaithersburg, Maryland) was used at the concentration of $1 \mathrm{ng} / \mathrm{ml}$, which was tested to optimally induct ICAM-1 expression by HMECs.

\section{Isolation of RNA and RT-PCR}

The total RNA was isolated with TRlzol reagent (GIBCO). The RNA was resuspended in RNase-free water and the concentration was measured. The RTPCR reagent kit (Promega, Madison, Wisconsin) and one-step RT-PCR method were used. The PCR mixture was prepared according to the kit instructions. The reaction was set up as follows: for all template RNA, $48^{\circ} \mathrm{C}$ for 45 minutes for reverse transcription and $94^{\circ} \mathrm{C}$ for 2 minutes for AMV reverse transcriptase inactivation and RNA/cDNA/primer denaturation. The conditions for PCR reactions were denaturation, $94^{\circ} \mathrm{C}, 30$ seconds; annealing, $60^{\circ} \mathrm{C}$ for VCAM-1 and $\beta$-actin and $55^{\circ} \mathrm{C}$ for ICAM- 1 for 1 minute; and extension, $72^{\circ} \mathrm{C}$ for 2 minutes. PCR primers for ICAM-1, VCAM-1, E-selectin, and $\beta$-actin were designed based on the published sequences (Grafe et al, 1997; Matsuzaki et al, 1996; Westergren et al, 1997). For quantification analysis, the PCR with primers for ICAM- 1 and the internal standard $\beta$-actin were performed in separate tubes using the same conditions and amounts of template RNA. The PCR product was analyzed by electrophoresis on $2 \%$ agarose gel and stained with ethidium bromide. The band density was determined by using image analysis software (Scion, Frederick, Maryland). All of the PCR products were sequenced and found to match the target RNA sequences.

\section{Immunofluorescence}

The cells were cultured in 4-well chamber slides, which were fixed with $4 \%$ formaldehyde and incubated with 5\% normal goat serum in PBS for 30 minutes. The slides were incubated with primary antibodies $(0.1 \%)$ overnight at $4^{\circ} \mathrm{C}$, then with secondary antibodies for 1 hour at room temperature in the dark. 
The slides were cover slipped with Immuno Floure Mounting Medium (ICN). The concentration for each antibody was as follows: anti-Von Willebrand factor antibody, 1:100; anti-ICAM-1 antibody, 1:100; FITC conjugated rabbit antibody, 1:50; and rhodamine conjugated goat anti-mouse immunoglobulins, 1:50.

\section{Soluble ICAM-1 Immunoassay}

The HMEC supernatants were collected and the ELISA kit (R and D Systems, Minneapolis, Minnesota) was used. This assay used the quantitative sandwich enzyme immunoassay technique, and the procedure was performed as described in the kit.

\section{Monocyte Adhesion Assay}

The adhesion of the THP-1 human monocytic cell line to HMECs was determined as described (Ouchi et al, 1999). Briefly, confluent HMECs in 12-well plates were exposed to gp120 $(5 \mu \mathrm{g} / \mathrm{ml})$ for 16 hours, and then the monolayer was rinsed and overlaid with THP-1 monocytes labeled with BCECF-AM (Molecular Probes, Eugene, Oregon) at $1 \times 10^{6} \mathrm{cells} / \mathrm{ml}$. After 1 hour of incubation with gentle rotational shaking, nonadherent cells were removed by gentle rinsing and the wells were washed extensively. Six random fields were captured using a CCD camera and fluorescence microscope. Adherent monocytes were counted as the number of adherent cells per field by image analysis (Alpha Innotech Corporation, San Leandro, California).

\section{Statistical Analysis}

The data were presented as mean \pm standard error. Statistical differences were determined using Student's $t$ test, where appropriate. $p$ values less than 0.05 were considered statistically significant.

\section{Acknowledgements}

The following reagent was obtained through the National Institutes of Health AIDS Research and Reference Reagent Program, Division of AIDS, NIDS, NIH: recombinant HIV LAV envelope glycoprotein gp120 (Baculovirus) from ImmunoDiagnostics, Woburn, Massachusetts; and monoclonal antibody to HIV-1 gp120 (IgG1 b12) from Dr. Dennis Burton and Dr. Carlos Barbas.

\section{References}

Adams MR, McCredie R, Jessup W, Robinson J, Sullivan D, and Celermajer DS (1997). Oral L-arginine improves endothelium-dependent dilatation and reduces monocyte adhesion to endothelial cells in young men with coronary artery disease. Atherosclerosis 129:261-269.

Ades EW, Candal FJ, Swerlick RA, George VG, Summers S, Bosse DC, and Lawley TJ (1992). HMEC-1: Establishment of an immortalized human microvascular endothelial cell line. $\mathrm{J}$ Invest Dermatol 99:683-690.

Annunziata P, Cioni C, Toneatto S, and Paccagnini E (1998). HIV-1 gp120 increases the permeability of rat brain endothe- lium cultures by a mechanism involving substance P. AIDS 12:2377-2385.

Banks WA, Akerstrom V, and Kastin AJ (1998). Adsorptive endocytosis mediates the passage of HIV-1 across the blood-brain barrier: Evidence for a post-internalization coreceptor. J Cell Sci 111:533-540.

Banks WA, Ibrahimi F, Farr SA, Flood JF, and Morley JE (1999). Effects of wheatgerm agglutinin and aging on the regional brain uptake f HIV-1 gp120. Life Sci 65:81-89.

Banks WA, Kastin AJ, and Akerstrom V (1997). HIV-1 protein gp120 crosses the blood-brain barrier: Role of adsorptive endocytosis. Life Sci 61:PL119-PL125.

Bazan HA, Alkhatib G, Broder CC, and Berger EA (1998). Patterns of CCR5, CXCR4, and CCR3 usage by envelope glycoproteins from human immunodeficiency virus type 1 primary isolates. J Virol 72:4485-4491.

Berendt AR, Simmons DL, Tansey J, Newbold Cl, and Marsh $\mathrm{K}$ (1989). Intercellular adhesion molecule-1 is an endothelial cell adhesion receptor for Plasmodium falciparum. Nature 341:57-59.

Borghi MO, Panzeri P, Shattock R, Szozzani S, Dobrina A, and Meroni PL (2000). Interaction between chronically HIVinfected promonocytic cells and human umbilical vein endothelial cells: Role of proinflammatory cytokines and chemolines in viral expression modulation. Clin Exp Immunol 120: 93-100.

Bragardo M, Buonfiglia D, Feito MJ, Bonissoni S, Redoglia V, Rojo JM, Ballester S, Portoles P, Garbarino G, Malavasi F, Dianzani U (1997). Modulation of lymphocyte interaction with endothelium and homing by HIV-1 gp120. J Immunol 159: 1619-1627.

Butini L, De Fougerolles AR, Vaccarezza M, Graziosi C, Cohen DI, Montroni M, Springer TA, Pantaleo G, and Fauci AS (1994). Intercellular adhesion molecules (ICAM)-1, ICAM-2, and ICAM-3 function as counter-receptors for lymphocyte function-associated molecule 1 in immunodeficiency virus-mediated syncytia formation. Eur $\mathrm{J}$ Immunol 24:2191-2195.

Butl R, Jaff H, Holroyd K, Borok Z, Roum JH, Mastrangeli A, Wells FB, Kirby M, Saltini C, and Crystal RG (1993). Activation of alveolar macrophages in asymptomatic HIV-infected individuals. J Immunol 150:1019-1028.

Capobianci MR (1996). Induction of lymphomonocyte activation by HIV-1 glycoprotein gp120. Possible role in AIDS pathogenesis. J Bio Regul Homeost Agents 10:83-91.

Cenacchi G, Re MC, Preda P, Pasquinelli G, Furlini G, Apkarian RP, La Placa M, and Martinelli GN (1992). Human immunodeficiency virus type-1 (HIV-1) infection of endothelial cells in vitro: A virological, ultrastructural and immnocytochemical approach. J Submicrosc Cytol Pathol 24:155161.

Chalifoux LV, Simon MA, Pauley DR, Mackey JJ, Wyand MC, and Ringler DJ (1992). Arteriopathy in macaques infected with simian immunodeficiency virus. Lab Invest 67:338-349.

Chen YH, Bock G, Vornhagen R, Steindl F, Katinger $H$, and Dierich MP (1994). HIV gp41 enhances major histocompatibility complex class I and ICAM-1 expression on $\mathrm{H} 9$ and U937 cells. Int Arch Allergy Appl Immunol 104:227-231.

Collins T, Read MA, Neish AS, Whitley MZ, Thanos D, and Maniatis T (1995). Transcriptional regulation of endothelial 
cell adhesion molecules: NF- $\kappa \mathrm{B}$ and cytokine-inducible enhancers. FASEB J 9:899-909.

Cominacini L, Pasini AF, Pastorino AM, Garbin U, Davoli A, Rigoni A, Campagnola M, Tosetti ML, Rossato P, and Gaviraghi $G$ (1999). Comparative effects of different dihydropyridines on the expression of adhesion molecules induced by TNF-alpha on endothelial cells. J Hypertens 17:1837-1841.

Constans J, Marchand JM, Conri C, Peuchant E, Seigneur M, Rispal P, Lasseur C, Pellegrin JL, and Leng B (1995). Asymtomatic atherosclerosis in HIV-positive patients: A casecontrolled ultrasound study. Ann Med 27:683-685.

Dhawan S, Puri RK, Kumar A, Duplan H, Masson JM, and Aggarwal BB (1997). Human immunodeficiency virus-1-Tat protein induces the cell surface expression of endothelial leukocyte adhesion molecule-1, vascular cell adhesion molecule-1, and intercellular adhesion molecule-1 in human endothelial cells. Blood 90:1535-1544.

Finco O, Nuti S, De Magistris MT, Mangiavacchi L, Aiuti A, Forte P, Fantoni A, van der Putten H, and Abrignani S (1997). Induction of CD4 + T cell depletion in mice doubly transgenic for HIV gp120 and human CD4. Eur J Immunol 27:13191324.

Flores S, Marecki J, Harper K, Bose S, Nelson S, and McCord J (1993). Tat protein of human immunodeficiency virus type 1 represses expression of manganese superoxide dismutase in HeLa cells. Proc Natl Acad Sci USA 90:76327636.

Fortin JF, Cantin R, Lamontagne G, and Tremblay M (1997). Host-derived ICAM-1 glycoproteins incorporated on human immunodeficiency virus type- 1 are biologically active and enhance viral infectivity. J Virol 71:3588-3596.

Galea P, Vermot-Desroches C, Le Contel C, Wijdenes J, and Chemann JC (1997). Circulating cell adhesion molecules in HIV1-infected patients as indicator markers for AIDS progression. Res Immunol 148:109-117.

Gilles PN, Lathey JL, and Spector SA (1995). Replication of macrophage-tropic and T-cell-tropic strains of human immunodeficiency virus type $\mathrm{I}$ is augmented by macrophageendothelial cell contact. J Virol 69:2133-2139.

Grafe M, Auch-Schwelk W, Zakrzewicz A, Regitz-Zagrosek V, Bartsch P, Graf K, Loebe M, Gaehtgens P, and Fleck E (1997). Angiotensin II-induced leukocyte adhesion on human coronary endothelial cells is mediated by E-selectin. Circ Res 81:804-811.

Green DF, Resnick L, and Bourgoignie JJ (1992). HIV infects glomerular endothelial and mesangial but not epithelial cells in vitro. Kidney Int 41:956-960.

Greenwood AJ, Hughes J, Wallace G, Seed P, Stanford MR, and Graham EM (1998). Soluble intercellular adhesion molecule-1 (sICAM-1) and vascular cell adhesion molecule-1 (sVCAM-1) in patients with HIV/AIDS does not appear to correlate with cytomegalovirus retinitis. Int J STD AIDS 9:713-714.

Gruber MF, Webb DS, Gerrard TL, Mostowski HS, Vujicic L, and Golding $H$ (1991). Reevaluation of the involvement of the adhesion molecules ICAM-1/LFA-1 in syncytia formation of HIV-1-infected subclones of a CEM T-cell leukemic line. AIDS Res Hum Retroviruses 7:45-53.

Guo MML and Hildreth JEK (1995). HIV acquires functional adhesion receptors from host cells. AIDS Res Hum Retroviruses 11:1007-1013.
Huang MB, Hunter M, and Bond VC (1999). Effect of extracellular human immunodeficiency virus type 1 glycoprotein gp120 on primary human vascular endothelial cell cultures. AIDS Res Hum Retroviruses 15:1265-1277.

Kalogeris TJ, Laroux FS, Cockrell A, Ichikawa H, Okayama N, Phifer TJ, Alexander JS, and Grisham MB (1999). Effect of selective proteasome inhibitors on TNF-induced activation of primary and transformed endothelial cells. Am J Physiol 276:C856-C864.

Lahdevirta J, Maury CPJ, Teppo AM, and Repo H (1988). Elevated levels of circulating eachectin/tumor necrosis factor in patients with acquired immunodeficiency syndrome. Am J Med 48:405-415.

Matsuzaki Z, Okamoto Y, Sarashina N, Ito E, Togawa K, and Saito I (1996). Induction of intercellular adhesion molecule-1 in human nasal epithelial cells during respiratory syncytial virus infection. Immunology 88:565-568.

Moses AV, Bloom FE, Pauza CD, and Nelson JA (1993). Human immunodeficiency virus infection of human brain capillary endothelial cells occurs via a CD4/ gagctosylceramide-independent mechanism. Proc Natl Acad Sci USA 90:10474-10478.

Mrowiec T, Melchar C, and Gorski A (1997). HIV proteinsmediated alternations in $\mathrm{T}$ cell interactions with the extracellular matrix proteins and endothelium. Arch Immunol Ther Exp 45:255-259.

Nottet HS (1999). Interactions between macrophages and brain microvascular endothelial cells: Role in pathogenesis of HIV-1 infection and blood-brain barrier function. J Neurovirol $5: 659-669$.

Nottet HS, Persidsky Y, Sasseville VG, Nukuna AN, Bock P, Zhai QH, Sharer LR, McComb RD, Swindells S, and Soderland C (1996). Mechanism for the transendothelial migration of HIV-1-infected monocytes in brain. J Immunol 40:611617.

Oh SK, Cruikshank WW, Raina J, Blanchard GC, Adler WH, Walker J, and Kornfeld H (1992). Identification of HIV-1 envelope glycoprotein in the serum of AIDS and ARC patients. J Acquir Immune Defic Syndr 5:251-265.

Ouchi N, Kihara S, Arita Y, Maeda K, Kuriyama H, Okamoto Y, Hotta K, Nishida M, Takahashi M, Nakamura T, Yamashita S, Funahashi T, and Matsuzawa Y (1999). Novel modulator for endothelial adhesion molecules: Adipocyte-derived plasma protein adiponectin. Circulation 100:2473-2476.

Pillet S, Prevost MH, Preira A, Girard PM, Rogine N, Hakim J, Gougerot-Pocidalo MA, and Elbim C (1999). Monocyte expression of adhesion molecules in HIV-infected patients: Variations according to disease stage and possible pathogenic role. Lab Invest 79:815-822.

Sawyer LS, Wrin MT, Craford-Miksza L, Potts B, Wu Y, Weber PA, Alfonso RD, and Hanson CV (1994). Neutralization sensitivity of human immunodeficiency virus type 1 is determined in part by the cell in which the virus is propagated. J Virol 68:1342-1349.

Scheglovitova O, Scanio V, Fais S, Papadia S, Abbate I, Castilletti C, Dianzani F, and Capobianchi MR (1995). Antibody to ICAM-1 mediates enhancement of HIV-1 infection of human endothelial cells. Arch Virol 140:951-958.

Seigneur M, Constans J, Blann A, Renard M, Pellegrin JL, Amiral J, Boisseau M, and Conri C (1997). Soluble adhesion 
molecules and endothelial cell damage in HIV-infected patients. Thromb Haemost 77:646-649.

Shatrov VA, Ratter F, Gruber A, Drobe W, and Lehmann V (1996). HIV type 1 glycoprotein 120 amplifies tumor necrosis factor-induced NF-kB activation in Jurkat cells. AIDS Res Hum Retroviruses 12:1209-1215.

Shrikant P, Benos DJ, Tang LP, and Benvenist EN (1996). HIV glycoprotein 120 enhances intercellular adhesion molecules-1 gene expression in glial cells: Involvement of Janus kinase/signal transducer and activator of transcription and protein kinease C signaling pathways. J Immunol 156: $1307-1314$

Shrikant PIY, Chung M, Ballestas M, and Benveniste NE (1994). Regulation of intercellular adhesion molecule-1 gene expression by tumor necrosis factor- $\alpha$, interleukin- $1 \beta$, and interferon- $\gamma$ in astrocyte. J Neuroimmunol 51:209-220.

Springer TA (1994). Traffic signals for lymphocytes recirculation and leukocyte migration: The multistep paradigm. Cell 67:301-314.

Stefano GB, Salzet M, and Bilfinger TV (1998). Long-term exposure of human blood vessels to HIV gp120, morphine, and anandamide increases endothelial adhesion of monocytes: Uncoupling of nitric oxide release. J Cardiovasc Pharmacol 31:862-868.

Steffan AM, Lafon ME, Gendrault JL, Schweitzer C, Royer C, Jaeck D, Arnaud JP, Schmitt MP, Aubertin AM, and Kirn A (1992). Primary cultures of endothelial cells from the human liver sinosoid are permissive for human immunodifficiency virus type 1. Proc Natl Acad Sci USA 89:1582-1586.

Tabib A, Leroux C, Mornex JF, and Loire R (2000). Accelerated coronary atherosclerosis and artheriosclerosis in young human-immunodeficiency-virus-positive patients. Coron Artery Dis 11:41-46.
Toneatto S, Finco O, van der Putten $\mathrm{H}$, Abrignani $\mathrm{S}$, and Annunziata P (1999). Evidence of blood-brain barrier alteration and activation in HIV-1 gp120 transgenic mice. AIDS 13:2343-2348.

Ullrich CK, Groopman JE, and Ganju RK (2000). HIV-1 gp120 and gp160-induced apoptosis in cultured endothelial cells is mediated by caspasses. Blood 96:1438-1442.

Westendorp MO, Shatrov VA, Schulze-Osthoff K, Frank R, Kraft M, Los M, Krammer PH, Droge W, and Lehmann V (1995). HIV-1 Tat potentiates TNF-induced NF-kappa B activation and cytotoxicity by altering the cellular redox state. EMBO J 14:546-554

Westergren V, Viale G, Dell'Orto P, Pellegrini C, and Hellquist HB (1997). RANTES is more prevalent in bacterial than in nonbacterial maxillary sinusitis: And P-selectin is preferentially up-regulated in diseased mucosae. Arch Otolaryngol Head Neck Surg 123:1103-1110.

White JM and Littman DR (1998). Viral receptors of the immunoglobulin superfamily. Cell 56:725-728.

Yao Q, Kuhlmann FM, Eller R, Compans RW, and Chen C (2000). Production and characterization of simian-human immunodeficiency virus-like particles. AIDS Res Hum Retroviruses 16:227-236.

Zietz C, Hotz B, Surzl M, Rauch E, Penning R, and Lohrs U (1996). Aortic endothelium in HIV-1 infection: Chronic injury, activation, and increase leukocyte adherence. Am J Pathol 149:1887-1898. 